\title{
Attainment Effects of Student Loans and Pell Grants Online Appendix
}

Benjamin M. Marx and Lesley J. Turner

January 2019 


\section{Appendix A: Additional Figures}

Figure A.1: Effects of Pell Grant Eligibility and Pell Grant Aid: Robustness of Estimates to Bandwidth Choice
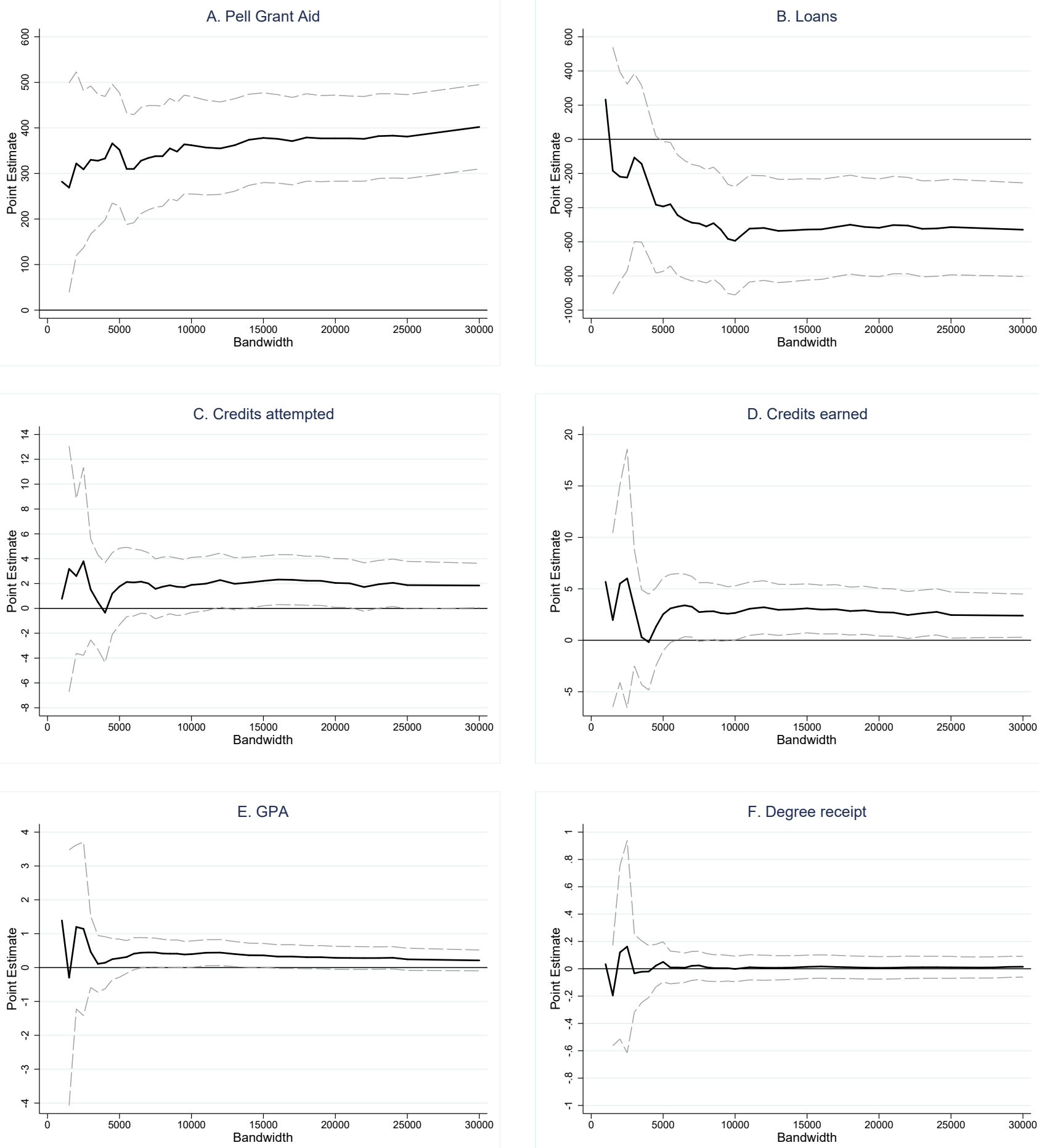

Notes: Sample includes enrolled CCA students who were randomly assigned before October 15, 2015 and who had an EFC within the specified bandwidth. Panels A and B contain OLS estimates of the impact of assignment to the treatment group and Pell Grant eligibility on Pell Grant aid, respectively. Panels C through F contain 2SLS estimates of the impact of an additional $\$ 1000$ in Pell Grant aid on the specified outcome; assignment to the treatment group and Pell Grant eligibility serve as excluded instruments. See Table 1 notes for specification and additional details. 
Figure A.2: Pell Grant Aid by Distance to the Pell Grant Eligibility Threshold

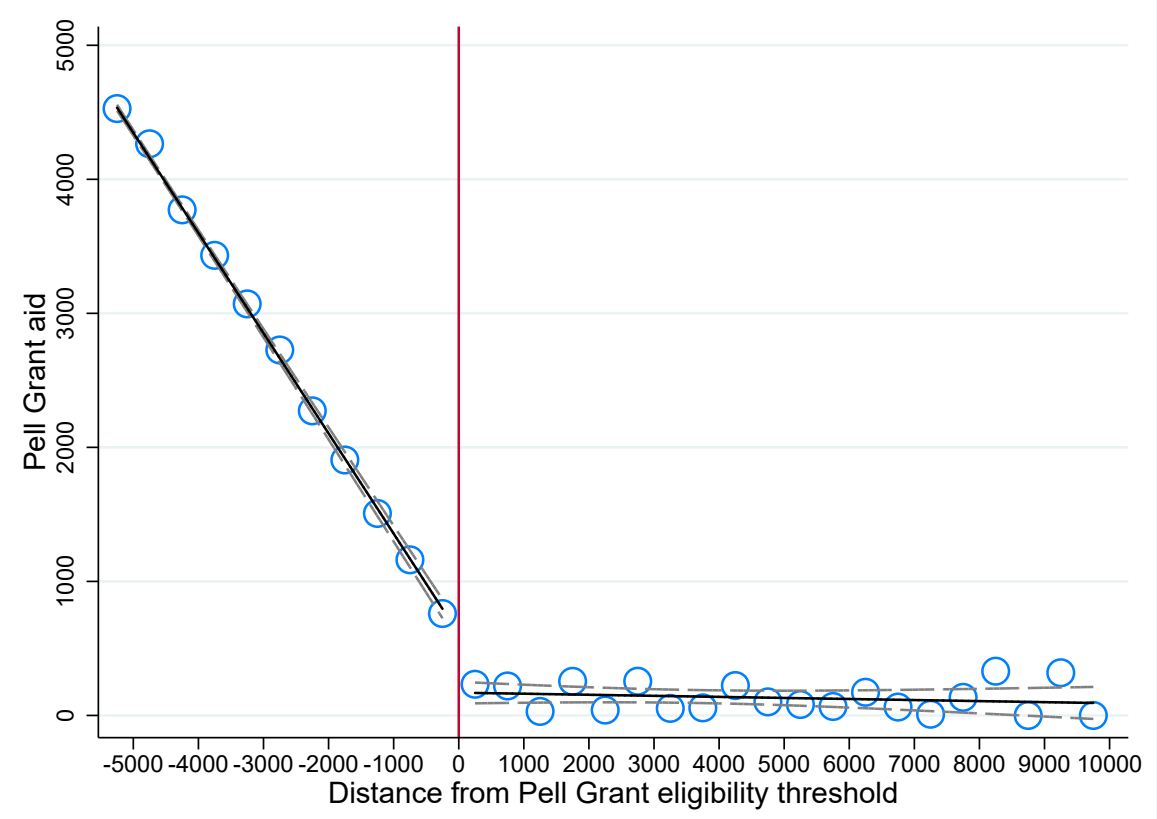

Notes: Sample includes enrolled CCA students who were randomly assigned before October 15, 2015 and who had an EFC less than $\$ 10,000$ above the Pell Grant eligibility threshold. $\$ 500$ EFC bins. Hollow circle markers indicate the average Pell Grant aid received within the EFC bin. Dark lines represent a linear fit of the bin averages on distance to the eligibility threshold, , weighted by the underlying sample size in each bin; dashed light lines are 95 percent confidence intervals. 
Figure A.3: Academic Outcomes by Distance to the Pell Grant Eligibility Threshold
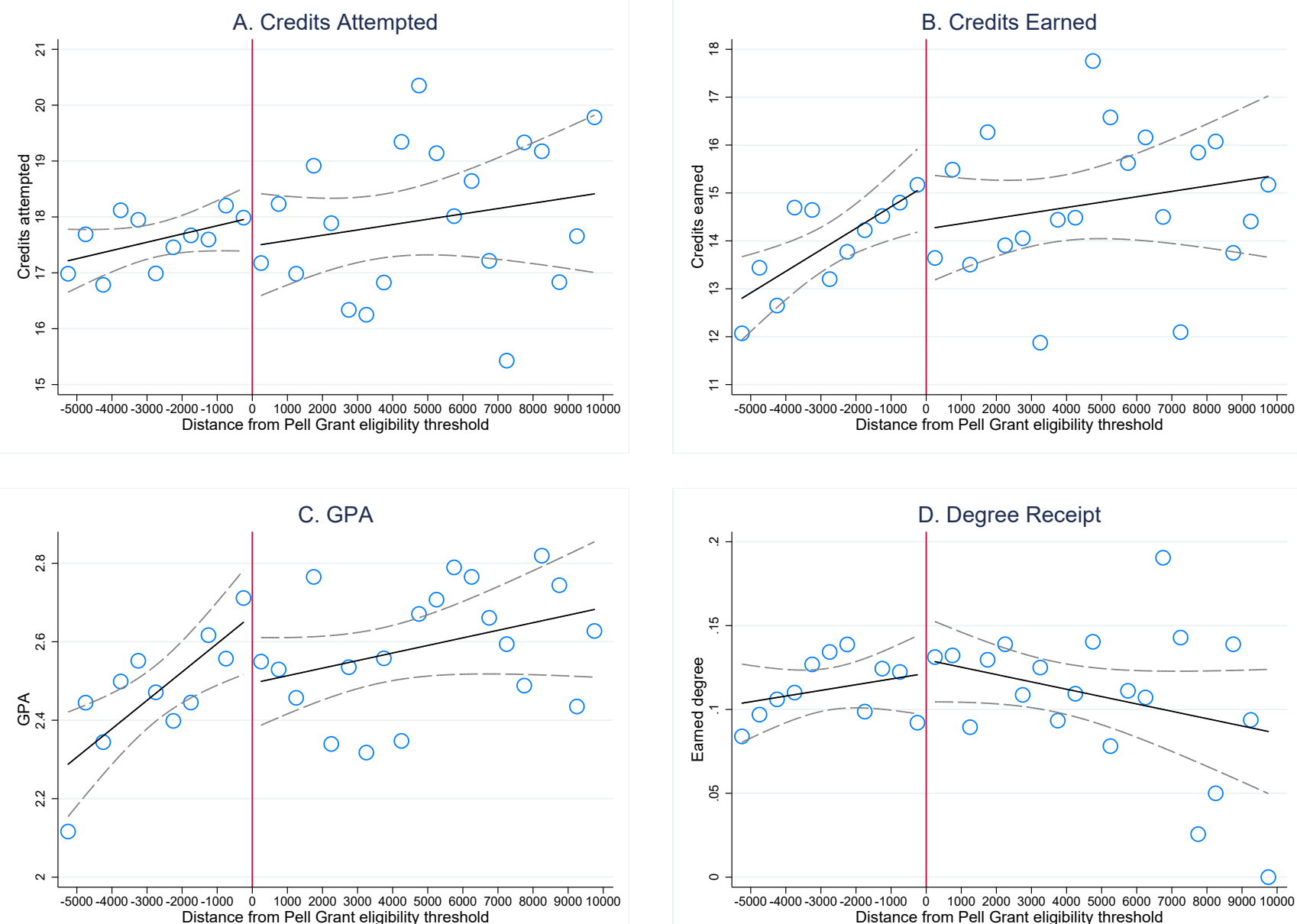

Notes: Sample includes enrolled CCA students who were randomly assigned before October 15, 2015 and who had an EFC less than $\$ 10,000$ above the Pell Grant eligibility threshold. $\$ 500$ EFC bins. Hollow circle markers indicate the average of the specified outcome within the EFC bin. Dark lines represent a linear fit of the bin averages on distance to the eligibility threshold, weighted by the underlying sample size in each bin; dashed light lines are 95 percent confidence intervals. 


\section{Appendix B: Validity of the RD Identifying Assumptions}

Figure B.1: Predetermined Characteristics by Distance to the Pell Grant Eligibility Threshold
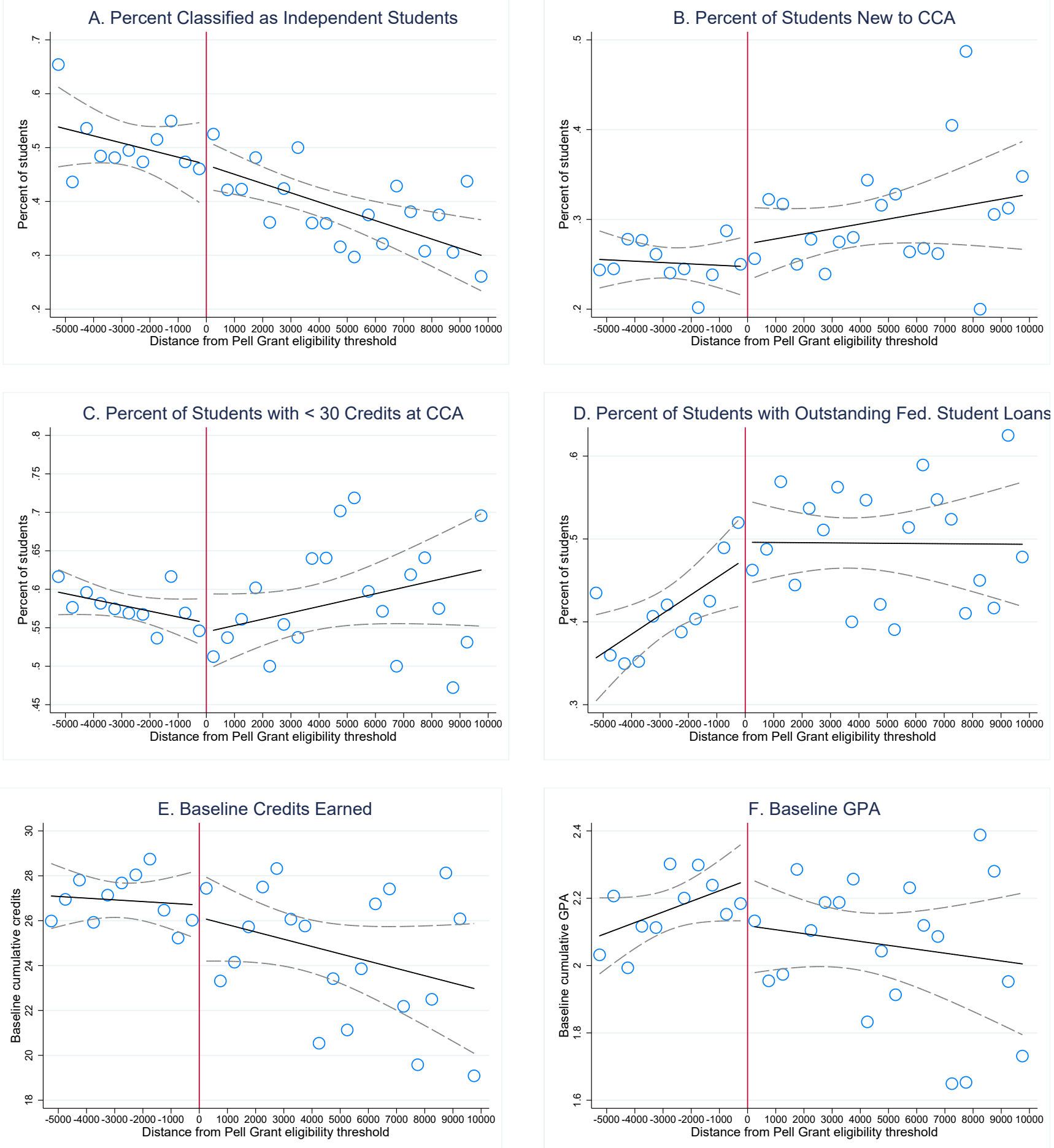

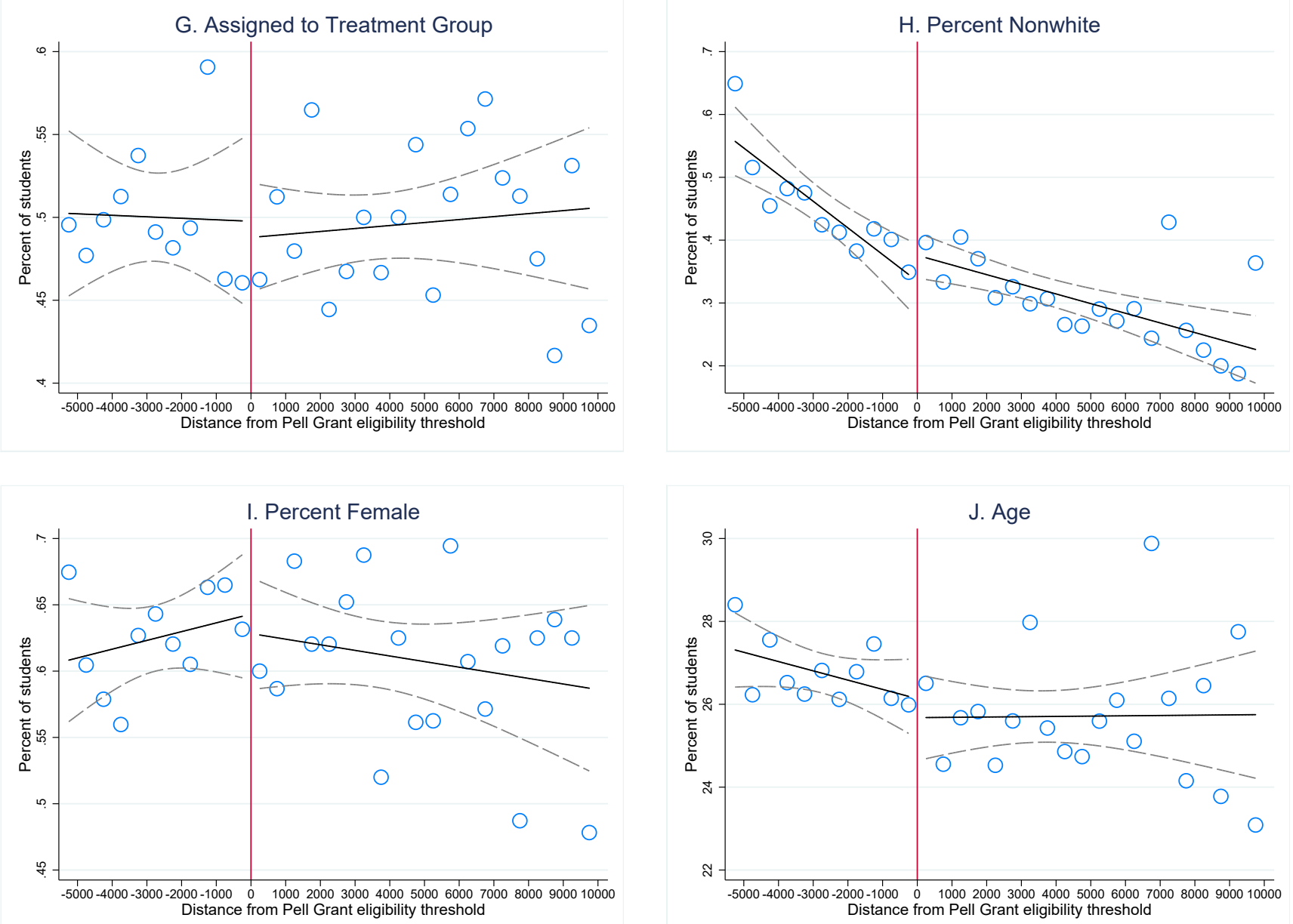

Notes: Sample includes enrolled CCA students who were randomly assigned before October 15, 2015 and who had an EFC less than $\$ 10,000$ above the Pell Grant eligibility threshold. $\$ 500$ EFC bins. Hollow circle markers indicate the average of the specified characteristic within the EFC bin. Dark lines represent a linear fit of the bin averages on distance to the eligibility threshold, weighted by the underlying sample size in each bin; dashed light lines are 95 percent confidence intervals. 
Figure B.2: Number of Students by Distance to the Pell Grant Eligibility Threshold

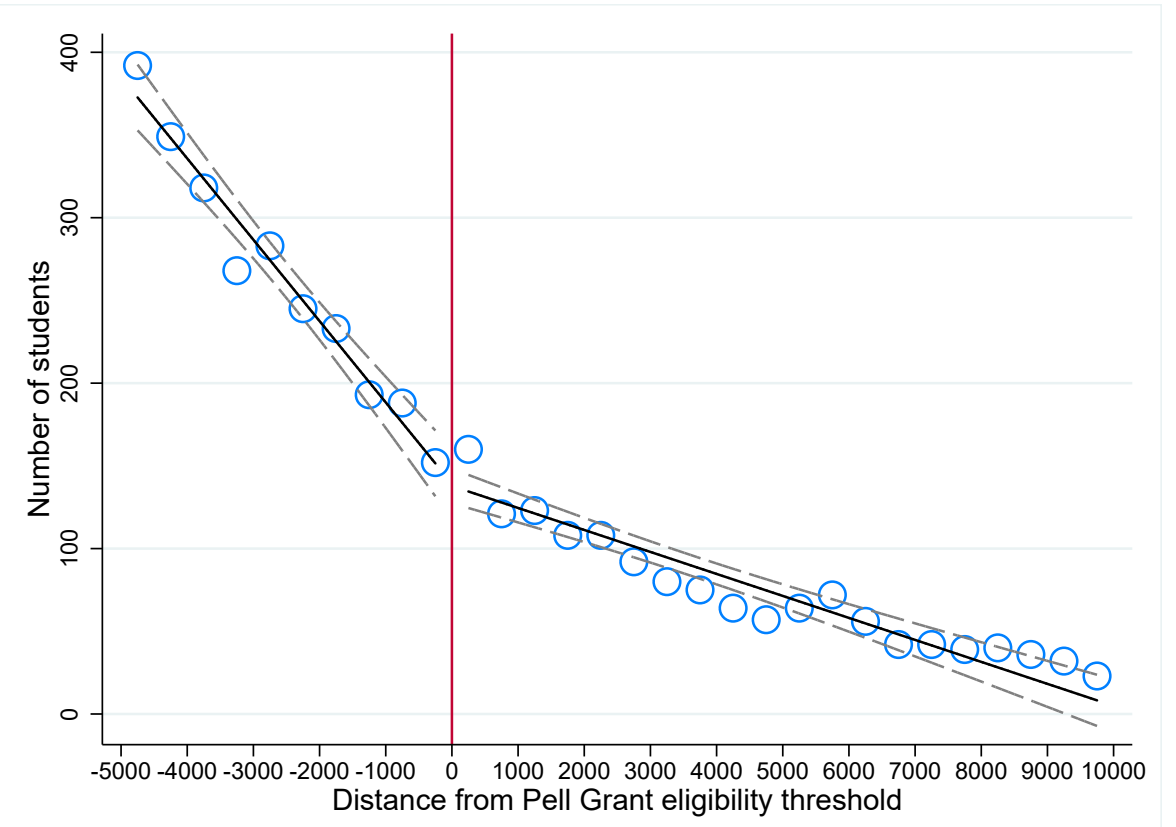

Notes: Sample includes enrolled CCA students who were randomly assigned before October 15, 2015 and who had an EFC less than $\$ 10,000$ above the Pell Grant eligibility threshold. $\$ 500 \mathrm{EFC}$ bins. Hollow circle markers indicate the number of students with an EFC in the bin. Larger circles indicate a larger underlying sample size. Dark lines represent a linear fit of the bin averages on distance to the eligibility threshold, weighted by the underlying sample size in each bin; dashed light lines are 95 percent confidence intervals. The bin corresponding to an EFC of zero is not shown $(\mathrm{N}=7053)$. McCrary test statistic (including $\mathrm{EFC}=0): 0.078(0.110)$. 